\title{
Impacto do Programa Bolsa Familia sobre as Decisões de Trabalho das Crianças: uma Análise utilizando os Microdados da PNAD
}

\section{Impact of the Conditional Cash transfer Bolsa Familia on the Decisions of Child Labor: an Analysis using PNAD Microdata}

\author{
Adriana Rosa do Nascimento* \\ Ana Lúcia Kassouf **
}

\begin{abstract}
Resumo: Em 2011, 4,33\% das crianças entre 5 e 15 anos trabalhavam ou exerciam atividade para consumo próprio ou construção civil para uso próprio. O objetivo principal deste trabalho é examinar o impacto do Programa Bolsa Família sobre o trabalho infantil. O impacto é estimado através do método de propensity score matching. Também se estimam regressões utilizando, alternativamente, a renda proveniente de transferência social como variável explicativa. Os dados utilizados são os da Pesquisa Nacional por Amostra de Domicílios (PNAD) de 2011. O resultado mostra que o programa não tem impacto significativo sobre a probabilidade de a criança trabalhar e sobre as horas trabalhadas. Adicionalmente, observa-se que a renda proveniente de transferência social tem impacto negativo e significativo sobre a probabilidade de a criança trabalhar e sobre o número de horas trabalhadas. Assim, embora a participação no programa não tenha impacto sobre o trabalho infantil, a renda proveniente do programa atua no sentido de reduzir a probabilidade de a criança trabalhar e o número de horas trabalhadas.
\end{abstract}

Palavras-chave: Trabalho infantil. Programa Bolsa Família. PNAD.

Abstract: In 2011, 4.33\% of children between 5 and 15 years were working or engaged in activity for own consumption or building for their own use. The main goal of this paper is to examine the impact of the conditional cash transfer program Bolsa Família on child labor. The impact was estimated by the method of propensity score matching. Also was estimated regressions using, alternatively, income from conditional cash transfers as an explanatory variable. The data used are from the Pesquisa Nacional por Amostra de Domicílio (PNAD), the Brazilian annual household survey of 2011. The results show that the program has no significant impact on the probability of work and on hours worked. Additionally, it is observed that the income from social cash transfer has negative and significant impact on the probability of child work and on the number of hours worked. Thus, although participation in the program has no impact on child

* $\quad$ Mestre em Economia Aplicada pela Escola Superior de Agricultura Luiz de Queiroz (Esalq), da Universidade de São Paulo (USP). Tutora dos cursos de Tecnologia em Processos Gerenciais e Tecnologia em Gestão de Recursos Humanos da Faculdade Cenecista de Osório. E-mail: adrianaeco28@gmail.com

* * Doutora em Applied Economics pela University of Minnesota. Professora titular do Departamento de Economia da Escola Superior de Agricultura Luiz de Queiroz (Esalq), da Universidade de São Paulo (USP). E-mail: anakassouf@usp.br 
labor, the income from the program acts to reduce the probability of child labor and the number of hours worked.

Keywords: Child labor. Bolsa Familia. PNAD. Brazil.

JEL Classification: H53; J29; C50.

\section{Introdução}

De acordo o Fundo das Nações Unidas para a Infância (2012), em 2011 cerca de 150 milhões de crianças entre 5 e 14 anos trabalhavam em países em desenvolvimento, o que representa $16 \%$ do total de pessoas nessa faixa etária. O efeito nocivo do trabalho para o bem-estar da criança depende das circunstâncias em que esse trabalho é realizado e do que a criança estaria fazendo na ausência do trabalho (EDMONDS; PAVCNIK, 2005).

O próprio termo "trabalho infantil" assume diversas definições conforme o autor que o utiliza e os dados que estão disponíveis para as pesquisas empíricas. Em estudos empíricos, usualmente se considera como trabalho infantil a atividade realizada por uma hora ou mais na semana, remunerada ou não (KASSOUF, 2007). A definição de trabalho infantil adotada nesta pesquisa é semelhante a de Kassouf (2004), que considera como criança a pessoa de 5 a 15 anos que havia trabalhado na semana anterior à entrevista, produzira alimento para consumo próprio, trabalhara na construção para uso próprio, ou que não trabalhou na semana anterior por estar de férias ou ter sofrido problema de saúde.

Ainda de acordo com a Organização Internacional do Trabalho (2012), nem todo trabalho realizado por crianças é classificado como "trabalho infantil", devendo ser eliminado. A participação em afazeres domésticos que não afeta a saúde e os estudos das crianças e adolescentes - como, por exemplo, ajudar nas tarefas domésticas ou nos negócios da família - é, em geral, considerado positivo. Esse tipo de atividade auxilia no desenvolvimento de habilidades e disciplina, dá mais independência e melhora a autoconfiança, além de proporcionar alguma experiência para a vida adulta (CARDOSO; SOUZA, 2004; EDMONDS; PAVCNIK, 2005). O impasse ocorre quando o tempo despendido com trabalho não pode ser gasto com outras atividades, podendo prejudicar o desempenho escolar. A correlação negativa entre trabalho infantil e desempenho escolar, entretanto, pode ter sentido inverso, isto é, crianças com pior desempenho escolar e que frequentam escolas com pior estrutura tendem a ingressar mais cedo no mercado de trabalho, buscando neste uma alternativa (EDMONDS; PAVCNIK, 2005).

Para conseguir uma redução mais rápida do trabalho infantil, é preferível melhorar o sistema de educação e proporcionar incentivos financeiros para famílias pobres que enviam seus filhos à escola do que adotar medidas punitivas para evitar que as crianças tenham trabalho assalariado (EDMONDS; PAVCNIK, 2005). 
Há consenso na literatura especializada de que para combater o trabalho infantil é melhor estabelecer uma educação compulsória, cuja frequência às aulas seja mais fácil de monitorar do que a proibição do trabalho infantil propriamente (BASU, 1999; CARDOSO; SOUZA, 2004).

Em casos em que a criança realmente precisa trabalhar para que a família não fique na miséria completa, medidas coercitivas não são boas alternativas porque "empurram" as crianças para atividades ainda mais perigosas (BASU; TZANNATOS, 2003). Ao invés do uso de medidas coercitivas, Basu e Tzannatos (2003) sugerem o uso de medidas colaborativas, ou seja, intervenções que alteram o ambiente econômico dos tomadores de decisão, fazendo-os deixar a criança fora do trabalho sem precisar de coerção ou legislação.

Desse modo, um programa de transferência de renda que tenha como condicionalidade a presença escolar se mostra um possível caminho para mitigar o trabalho infantil. Essas transferências provenientes dos programas sociais provocam um efeito renda que leva à modificação da decisão da família sobre a alocação do tempo das crianças entre trabalho e educação (CACCIAMALI; TATEI; BATISTA, 2010). Embora não seja objetivo direto do programa, a redução do trabalho infantil é um efeito transbordamento esperado que este artigo pretende medir.

Diante disso, este trabalho tem como objetivo principal avaliar o impacto do Programa Bolsa Família sobre o status de trabalho de crianças, utilizando os dados da Pesquisa Nacional por Amostra de Domicílios (PNAD) de 2011. A modelagem econométrica utilizada para verificar como a participação no programa de transferência de renda impacta o status de trabalho de crianças é o propensity score matching. Esse modelo estima o impacto do programa na decisão de trabalhar através da construção de grupos de tratamento e controle, tornando possível a comparação dos resultados.

Este artigo está organizado em seis partes, além desta introdução. A seção 2 expõe a revisão de literatura realizada; a seção 3 apresenta as características do Programa Bolsa Família; a seção 4 tece um panorama geral do trabalho infantil no Brasil; a seção 5 trata da metodologia apresentando a fonte de dados e o método econométrico utilizado; a seção 6 apresenta os resultados e discussões das estimativas elaboradas. Por fim, a seção 7 encerra com algumas considerações finais.

\section{Revisão Bibliográfica}

Kassouf (2004) afirma que características familiares como nível de educação dos pais, número de irmãos, além da pobreza são alguns determinantes do trabalho infantil, o qual também depende da dinâmica do mercado de trabalho. Outro determinante da oferta de trabalho infantil é a habilidade da família em lidar com as flutuações de renda (CARDOSO, SOUZA, 2004). Juntamente com esses fatores, 
os estudos empíricos utilizam outras variáveis como determinantes do trabalho infantil. Kassouf (2007) resume essas variáveis - pobreza, nível de educação dos pais, número de irmãos, idade, chefe da família e área de residência.

Soares e Pianto (2003) discutem metodologias de avaliação de impacto do Programa de Erradicação do Trabalho Infantil (Peti) sobre o trabalho infantil, frequência escolar e renda e os resultados de uma avaliação para municípios que aderiram ao programa entre 1997 e 1999. Os autores usam matching de Heckman e "diferenças em diferenças" usando dados de municípios que aderiram ao programa, construindo um painel com 31 municípios que aparecem tanto nas PNADs de 1997 e 1998, quanto no Peti. Os resultados indicam que existe impacto do programa no sentido de diminuir o trabalho infantil. Nos municípios participantes do Peti, o trabalho infantil sofreu redução de 7,7 pontos percentuais em relação ao grupo de controle e o trabalho infantil degradante diminuiu 3 pontos percentuais, enquanto nos municípios não participantes houve aumento, o que levou o impacto do Peti para 4,3 pontos percentuais na redução de trabalho degradante de crianças.

Ferro e Kassouf (2005) analisam o impacto do programa Bolsa Escola sobre o trabalho infantil, esperando que programas de transferência de renda condicional à frequência escolar tenham um efeito transbordamento que leve a menor ocorrência de trabalho infantil devido ao fato da criança dispor de menos tempo para dedicar ao trabalho. As autoras estimam um modelo probit de oferta de trabalho e uma regressão linear por mínimos quadrados para o número de horas semanais trabalhadas. As variáveis de controle são gênero, raça, idade, idade dos pais, educação dos pais, logaritmo dos salários, além de uma binária para cada estado brasileiro. A variável de interesse, a binária para participação no programa, é significativa, mas tem sinal positivo, diverso do esperado, no modelo. Conforme os resultados, participar do programa aumenta a probabilidade de a criança trabalhar em $0,71 \%$ na zona urbana e 3,62\% na zona rural. Já para o modelo das horas trabalhadas, o impacto do Bolsa Escola tem o sinal esperado reduzindo o número de horas trabalhadas pela criança em 3,04 na zona urbana e em 2,8 horas na zona rural.

Em relação ao sinal não esperado do impacto do Bolsa Escola sobre a probabilidade de a criança trabalhar, as autoras argumentam que as famílias que recebem o benefício são também as mais passíveis de enviarem seus filhos para o trabalho. Ainda, aquelas famílias cujas crianças tem maior propensão a trabalhar por causa da pobreza, são também aquelas que têm maior propensão a ser beneficiadas pelo programa. Além disso, Ferro e Kassouf (2005) atentam para o fato de possivelmente existir uma variável omitida que resulta em um viés no coeficiente da variável de participação no Bolsa Família e tornando o sinal positivo, sendo essa variável omitida a "ambição" familiar. Isto é, na tentativa de melhorar o pa- 
drão de vida e deixar a pobreza, a família adota todas as estratégias disponíveis para aumentar a renda, de modo que todos na família trabalham e, mesmo assim, a família participa de programas sociais.

Cardoso e Souza (2004) estimam o impacto dos programas Bolsa Escola e Renda Mínima sobre a frequência escolar e o trabalho infantil utilizando dados do Censo de 2000 para crianças entre 10 e 15 anos e o método de propensity score. A transferência de renda do programa contribui para reduzir a incidência de crianças que apenas trabalham ou que não trabalham nem estudam e aumentar o número de crianças que trabalham e estudam ou apenas estudam, além de ser significativo na frequência escolar.

Cacciamali, Tatei e Batista (2010) analisam o impacto do Programa Bolsa Família sobre o trabalho infantil e a frequência escolar utilizando dados da PNAD de 2004 através de um modelo probit bivariado (uma equação para o fato de frequentar ou não a escola e outra para o fato da criança trabalhar ou não). Os resultados mostram que o programa é eficiente para aumentar a frequência escolar. No entanto, o fato de ser beneficiário do programa aumenta a probabilidade de incidência de trabalho infantil. Os autores alegam que o programa não tem como objetivo reduzir o trabalho infantil, mas apenas, entre outros, aumentar a frequência à escola.

Araújo, Ribeiro e Neder (2010) utilizam o propensity score matching e dados da PNAD de 2006 para avaliar o impacto do Bolsa Família sobre o trabalho de crianças beneficiárias da área urbana. Da amostra, foram eliminados os beneficiários do Peti para evitar os efeitos desse programa e famílias com renda mensal per capita de mais de $\mathrm{R} \$ 300,00$ (para melhorar o pareamento). Os resultados indicam que o programa aumenta a frequência escolar e diminui a ociosidade de crianças, embora o impacto seja pequeno. O número de crianças inativas foi reduzido com o programa em 1,2 ponto percentual e a proporção de crianças que apenas estudam e que estudam e trabalham aumentou em 0,8 pontos percentuais. Não houve impacto significativo sobre a proporção de crianças que trabalham ou trabalham e estudam. Ou seja, o programa aumenta a frequência escolar, mas não combate o trabalho infantil. Para adolescentes, o programa elevou em 5,2 pontos percentuais a proporção dos que apenas estudam e reduziu a proporção dos que trabalham (1,5 ponto percentual) e dos que são inativos (1,9 ponto percentual).

Ferro, Kassouf e Levison (2010) investigam o impacto do programa Bolsa Escola nas decisões de trabalho das famílias usando dados da PNAD de 2003. Essa pesquisa se beneficia do fato da PNAD de 2003 incluir perguntas específicas sobre participação no programa e sobre o fato de se estar inscrito para começar a receber o benefício, o que facilita a identificação dos receptores do benefício e a criação de um grupo de controle adequado formado por essas famílias que estavam esperando para receber o benefício. Os métodos de estimação do impacto 
utilizado são os modelos probit e propensity score matching. Os modelos têm como variáveis dependentes variáveis binárias indicadoras de trabalho e frequência escolar. Como variáveis de controle são utilizadas idade, cor, gênero, idade e escolaridade do pai e da mãe, diferença de idade entre pai e mãe, número de irmãos e região de residência. Os resultados encontrados indicam que o programa reduz a probabilidade das crianças de 6 a 15 anos trabalharem, aumenta a probabilidade de estudarem e aumenta a participação dos pais no mercado de trabalho.

Em anos mais recentes, Oliveira e Soares (2013) analisam o impacto do programa Bolsa Família sobre a repetência escolar utilizando dados do Cadastro Único para Programas Sociais do Governo Federal (CadÚnico) do Projeto Presença e do Censo Escolar. Os autores analisam o impacto do programa sobre a probabilidade da criança repetir a série na escola controlando para variáveis familiares e da escola. Também verificam que crianças beneficiárias do Bolsa Família têm menor probabilidade de repetência, mas que aumentos no valor da transferência não indicam maior ou menor probabilidade de reprovação. Apesar da evidência de que o Bolsa Família contribua para reduzir a repetência escolar, os autores fazem a ressalva de que como os dados do CadÚnico e do Censo Escolar são administrativos podem estar sujeitos a algumas falhas. Espera-se o aperfeiçoamento desses dados para se obter melhores estimativas.

\section{Programa Bolsa Familia}

O Programa Bolsa Família, integrante do Plano Brasil sem Miséria, é um programa de transferência de renda que visa aliviar e diminuir a pobreza e a vulnerabilidade. São consideradas famílias em condição de extrema pobreza, isto é, aquelas que possuem renda familiar per capita igual ou inferior a $R \$ 70,00$ mensais e famílias em condição de pobreza, ou seja, aquelas que possuem renda familiar per capita igual ou inferior a R \$140,00. A seleção das famílias que receberão o benefício é feita através dos dados do CadÚnico, o qual é realizado pelos municípios. No final de 2011, o programa beneficiava 13,3 milhões de famílias. Segundo Rocha (2011), o programa atendia, em 2007, 19,4\% dos domicílios brasileiros.

O programa, instituído pela Lei $n^{\circ}$ 10.836/04 (BRASIL, 2013b), e regulamentado pelo Decreto $n^{\circ}$ 5.209/04 (BRASIL, 2013a), teve, em 2013, um dispêndio de $\mathrm{R} \$ 24,5$ bilhões, atendendo 14,1 milhões de famílias (DUTRA, 2014).

De acordo com BRASIL (2013a), os objetivos do Bolsa Família são: a) promover o acesso a serviços públicos, sobretudo, de saúde, educação e assistência social; b) combater a fome e promover segurança alimentar e nutricional; c) estimular a emancipação de famílias que se encontram em situação de pobreza e extrema pobreza; d) combater a pobreza; e) promover a intersetorialidade e a complementaridade de ações sociais do poder público. 
Os benefícios que podiam ser recebidos pelas famílias, em 2011, eram: ${ }^{1}$

a) benefício básico: $R \$ 70,00$ para famílias de extrema pobreza;

b) benefício variável: $R \$ 32,00$ para famílias pobres e extremamente pobres com crianças entre 0 e 15 anos (no máximo três benefícios por família);

c) benefício variável vinculado ao adolescente: $R \$ 38,00$ para famílias pobres e extremamente pobres com jovens de 16 a 17 anos (no máximo dois benefícios);

d) benefício variável de caráter extraordinário: valor calculado para cada família transferida de outros programas para o Bolsa Família (aquelas que recebiam auxílios como Família Auxílio-Gás, Bolsa Escola, Bolsa Alimentação e cartão alimentação).

As famílias recebedoras do benefício se comprometem a: a) acompanhar o cartão de vacinação e o crescimento de crianças menores de 7 anos e de mulheres entre 14 e 44 anos; b) gestantes ou lactantes devem realizar o pré-natal; c) crianças entre 6 e 17 anos devem estar regularmente matriculadas na escola e ter frequência mensal de no mínimo $85 \%$ ao mês, caso tenham entre 6 e 15 anos, ou de $75 \%$ ao mês, caso tenham entre 16 e 17 anos; d) crianças até 15 anos participantes do Peti devem participar do Serviço de Convivência e Fortalecimento de Vínculos (SCFV) do Peti, tendo frequência de no mínimo 85\% ao mês.

Como a educação é correlacionada com o rendimento, fazer as famílias participantes enviarem seus filhos à escola, por exemplo, faz com que essas crianças tenham melhores oportunidades quando adultos, quebrando o ciclo de pobreza.

O Programa Bolsa Família não tem como meta explícita a erradicação do trabalho infantil. As condicionalidades do programa exigem, entre outras, apenas a frequência escolar das crianças beneficiadas, e não o abandono do trabalho eventualmente exercido. No entanto, a redução do trabalho infantil é uma consequência dos programas, visto que, ao se exigir a frequência a escola, diminui o tempo disponível para o trabalho (BARROS; MENDONÇA, 2011, CACCIAMALI; TATEI; BATISTA, 2010). Conforme Kassouf (2015, p. 24), "Uma vez que a condicionalidade educacional torna obrigatória a freqüência das crianças à escola, há redução do tempo despendido em outras atividades, inclusive no mercado de trabalho, o que acarreta redução do trabalho infantil."

Espera-se um efeito trasbordamento pelo menos sobre o número de horas trabalhadas, pois a criança disporá de menos tempo para trabalhar, uma vez que estará frequentando a escola regularmente. O presente artigo se propõe a verificar a existência desse efeito transbordamento, o qual não foi encontrado em algumas pesquisas empíricas, como a de Ferro e Kassouf (2005) - analisando o Bolsa Escola

1 Foram considerados os valores dos benefícios em 2011, visto que são desse ano os dados utilizados nas estimações. 
- e as de Cacciamali, Tatei e Batista (2010) e Araújo, Ribeiro e Neder (2010) - analisando o Bolsa Família.

\section{Trabalho Infantil no Brasil}

\subsection{Evolução do Trabalho Infantil ${ }^{2}$}

O Gráfico 1 apresenta a evolução do percentual de crianças que trabalham no Brasil no período 1992 a 2011 . $^{3}$ Tomando-se as crianças na faixa de 5 a 10 anos, verifica-se que no período em análise houve redução de aproximadamente 4,22 pontos percentuais na incidência de trabalho. No grupo etário de 11 a 15 anos, a presença de trabalho infantil é muito mais acentuada. Em 1992, mais de 24\% das crianças nessa idade trabalhavam, um percentual que se reduziu em quase 17 pontos percentuais, atingindo 8,04\% em 2011. Para todas as crianças de 5 a 15 anos, a redução na incidência de trabalho foi de mais de 10 pontos percentuais, exceto entre os anos de 2004 e 2005, quando houve leve aumento do percentual de crianças que trabalham. O número de crianças trabalhando se reduziu progressivamente durante todo o período considerado.

2 Todas as tabelas e gráficos desta seção foram elaborados com os dados da PNAD de vários anos considerando a amostra expandida. Deve-se observar que, como as PNADs de 1992 a 2003 não apresentam dados para a zona rural dos estados da região Norte, à exceção do estado de Tocantins, desconsidera-se das análises, salvo indicação contrária, os dados da zona rural desses estados também dos anos de 2004 a 2011. As PNADs de 1996 e 1997 não apresentam dados de trabalho para crianças de 5 a 9 anos e, por isso, também são desconsideradas na análise. Os dados foram tabulados utilizando-se o software Stata, e os gráficos construídos com o software Excel.

3 Nos anos de 2000 e 2010 não se realizou a PNAD por ser ano de censo. Em 1994, excepcionalmente também não houve PNAD. 
Gráfico 1 - Evolução do trabalho infantil

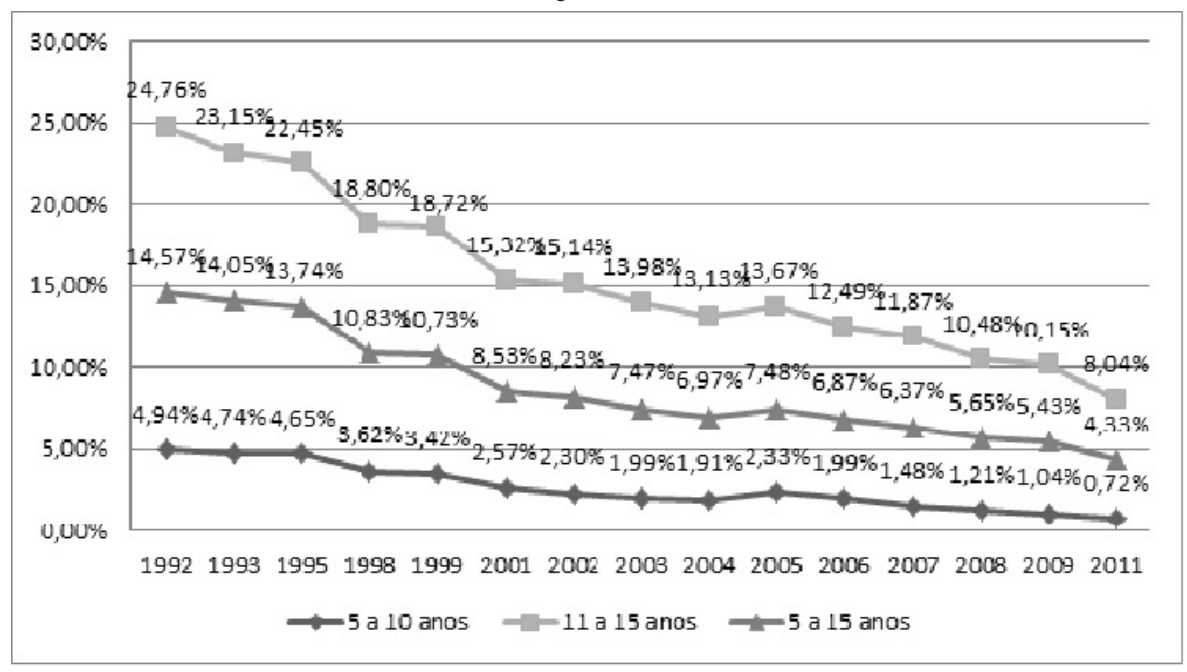

Fonte: Elaboração própria a partir de PNAD, vários anos.

Em 2011, atinge-se 4,33\% do total de crianças entre 5 e 15 anos exercendo atividades laborais. Para o grupo etário de 5 a 10 anos, a redução mais significativa ocorreu entre os anos de 1999 e 2001 e de 2006 e 2007. Já para as crianças entre 11 e 15 anos, destaca-se a redução entre os anos de 1992 e 1993 e entre 2009 e 2011. O próprio Bolsa Família foi criado em 2003, a partir da unificação do Programa Bolsa Escola (criado em âmbito nacional em 2001) a outros programas sociais. No entanto, esse programa não parece ter sido responsável por uma queda significativa do trabalho infantil no período logo após sua implementação. A longo prazo, porém, a redução do número de crianças trabalhando é mais visível, podendo ser devido à existência do programa e sua condicionalidade à frequência escolar, que reduziu o tempo disponível para o trabalho, como a mudança nos valores das empresas que passaram a não mais empregar mão de obra infantil, assim como a mentalidade das próprias famílias, as quais passaram a não querer que seus filhos trabalhassem.

O Gráfico 2 apresenta a atividade - somente estuda, somente trabalha, estuda e trabalha ou nem estuda nem trabalha - para crianças separadas por grupos etários nos anos de 1992, 2001 e 2011. Sobressai-se o fato do percentual de crianças que não trabalham nem estudam ter diminuído sobremaneira de 1992 até 2011. Em 1992, havia mais de 15\% de crianças de 5 a 15 anos sem realizar atividade alguma, percentual que cai quase pela metade em 2001 e atinge $3 \%$ em 2011. Notadamente, são principalmente as crianças mais novas que não frequentam a escola e tão pouco trabalham. As crianças, à medida que ficam mais velhas, 
realizam em geral pelo menos uma atividade e muitas vezes dividem o tempo entre estudo e trabalho - em 2011, 7,44\% das crianças entre 11 e 15 anos faziam as duas atividades contra menos de $1 \%$ das crianças de 5 a 10 anos. O percentual de crianças que apenas estudam aumentou quase 15 pontos percentuais entre $1992 \mathrm{e}$ 2001, ano de implementação do Bolsa Escola, aumentando cerca da metade disso entre 2001 e 2011. Pode-se inferir, com a diminuição simultânea do percentual de crianças sem realizar atividade alguma e que apenas trabalham, que estas passaram a somente estudar ou pelo menos a estudar e trabalhar.

Gráfico 2 - Crianças conforme a atividade que realizam separadas por grupos etários (anos selecionados)

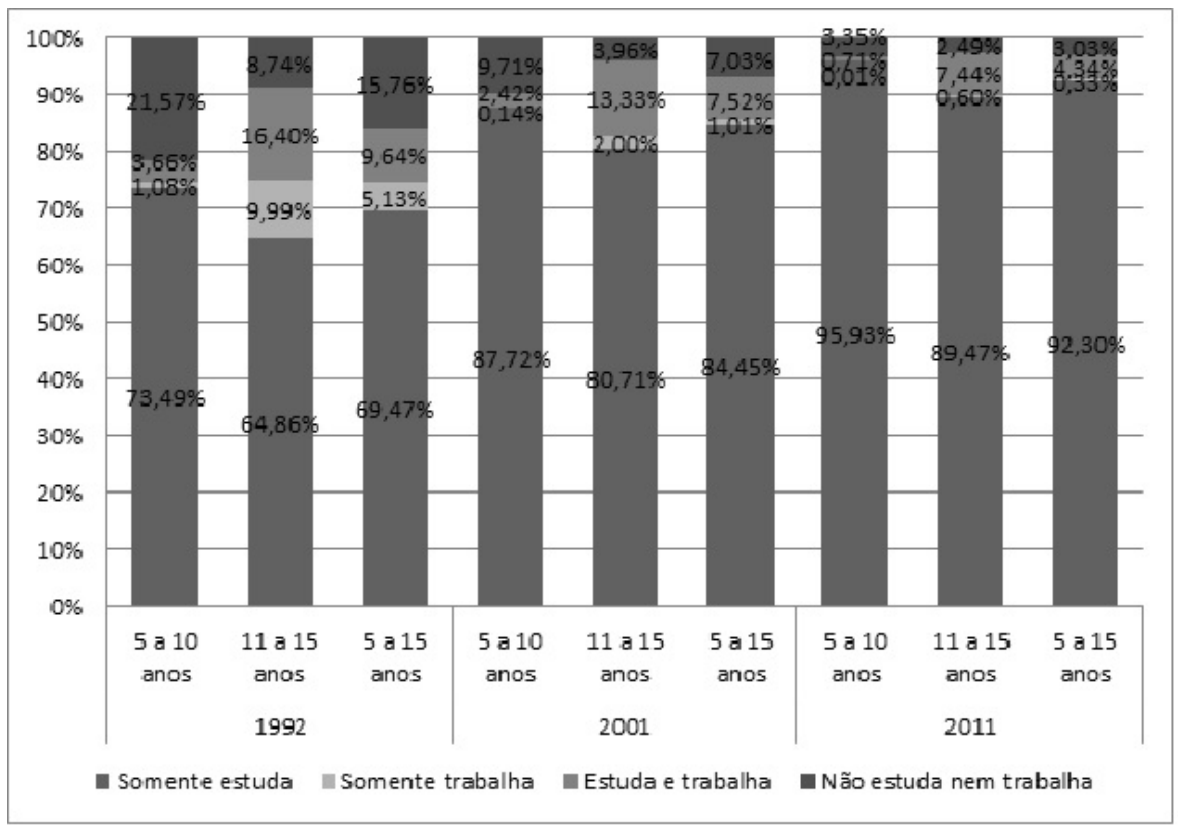

Fonte: Elaboração própria a partir de PNAD, vários anos.

O percentual de crianças trabalhando de 1992 a 2011, separando as crianças por faixa etária e gênero, é mostrado no Gráfico 3. Verifica-se que há maior percentual de meninos trabalhando do que de meninas. Deve-se considerar, entretanto, que muitas meninas exercem atividades no próprio lar, cuidando dos irmãos menores ou ajudando em atividades domésticas, o que não é contabilizado nessas estatísticas. A maior queda em pontos percentuais é para meninos de 11 a 15 anos, dentre os quais mais de 34\% trabalhavam em 1992 e pouco mais de $10 \%$ trabalhavam em 2011. Também se observa que a redução do trabalho infantil para todos os grupos foi mais acentuada entre 1992 e 2001, embora a tendência de 
queda continue no período posterior de forma moderada. Cabe lembrar que até 1998 era permitido o trabalho a partir dos 14 anos e, a partir de então, se admite o trabalho apenas aos 16 anos e como aprendiz a partir dos 14 anos. Essa modificação parece ter sido responsável pela redução muito pequena do trabalho infantil a curto prazo, pois entre 1998 e 1999, o percentual de meninos e meninas de 5 a 10 anos diminui 0,13 e 0,25 pontos percentuais, respectivamente, e o percentual de meninas de 11 a 15 anos chegou a aumentar ligeiramente nesse período. Em 2005 , ano em que houve aumento do trabalho infantil em relação ao ano anterior, ocorreu uma grave crise na agricultura, o que pode ser o motivo do aumento na incidência de crianças trabalhando, pois grande parte delas está em atividades ligadas à agricultura. Tomando-se as crianças de 5 a 15 anos que exercem atividade laboral, $65 \%$ delas são meninos para todos os anos considerados.

Gráfico 3 - Percentual de meninos e meninas trabalhando por grupos etários (1992 a 2011)

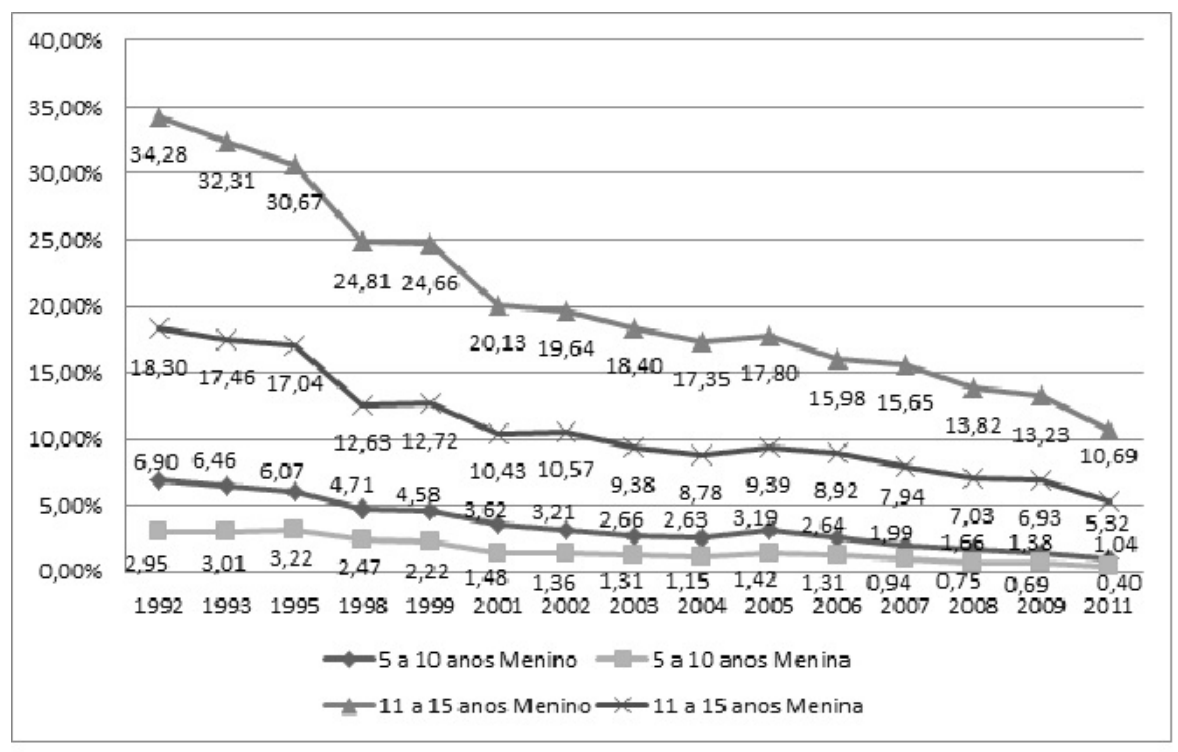

Fonte: Elaboração própria a partir de PNAD, vários anos.

\subsection{O Trabalho Infantil no Brasil em 2011}

Nesta subseção se detalham algumas estatísticas sobre o trabalho infantil utilizando os dados da PNAD de 2011. ${ }^{4}$ Cabe destacar que, em 2011, havia 1.666.750 crianças entre 5 e 15 anos trabalhando, das quais 160.100 (9,60\%) tinham de 5 a

4 Nesta subseção consideram-se também os dados da zona rural dos estados da região norte. 
10 anos e $1.506 .650(90,4 \%)$ de 11 a 15 anos, sendo que 1.134 .347 (68\%) eram meninos e 532.403 eram meninas (32\%).

No que se refere ao rendimento mensal, verifica-se que crianças entre 5 e 10 anos tiveram, em 2011, renda média de $R \$ 29,72$, enquanto aquelas de 11 a 15 anos receberam aproximadamente $\mathrm{R} \$ 114,00$ em média, por mês, fazendo o rendimento mensal médio para os trabalhadores infantis (faixa de 5 a 15 anos) ser de $R \$ 105,13 .^{5}$ Vale lembrar que entre as crianças de 5 a 15 anos que trabalhavam em 2011 , aproximadamente $56 \%$ não recebiam rendimento. ${ }^{6}$ Não receber pagamento pelo trabalho realizado é mais comum entre as crianças menores (5 a 10 anos), dentre as quais mais de $88 \%$ não recebe rendimentos em comparação com as crianças maiores (11 a 15 anos), das quais cerca de 52\% não recebem pagamento.

A Tabela 1 apresenta o percentual de crianças por ramo de atividade separadas por grupos de idade e gênero. Tomando-se o grupo como um todo, verifica-se que mais da metade $(56,39 \%)$ dos meninos trabalham em atividades relacionadas à agropecuária, pesca e silvicultura, ramo seguido pelo comércio que detém pouco mais de $18 \%$ da mão de obra masculina dessa idade. O ramo de serviços domésticos detém menos de $1 \%$ dos meninos, mas emprega quase $22 \%$ da mão de obra feminina entre 5 e 15 anos. Para as meninas, o ramo da agropecuária e atividades relacionadas também é importante fonte de ocupação, empregando $34 \%$ delas. Comércio e serviços também detêm parcela significativa das meninas que trabalham - 17\% e 16\%. respectivamente. Já a indústria emprega parcela semelhante de meninos e meninas $(7,33 \%$ e $8,77 \%$, respectivamente). O ramo da construção emprega apenas meninos, 5,5\% deles. As crianças mais novas (entre 5 e 10 anos) trabalham principalmente na agropecuária e em atividades relacionadas (83\% dos meninos e 66,45\% das meninas nessa faixa de idade), seguidas pelo comércio, que emprega quase $10 \%$ das crianças de 5 e 10 anos de ambos os gêneros. Quanto mais velhas, ocorre uma mudança no ramo de atividade das crianças - sobretudo das meninas -, da agricultura para o comércio (no qual estão quase $20 \%$ das crianças dessa idade) e serviços (que conta com 10\% dos meninos e mais de $17 \%$ das meninas de 11 a 15 anos). Os serviços domésticos também ganham importância com o aumento da idade para as meninas. Esse ramo conta com menos de $3 \%$ das meninas mais novas, mas com $23,43 \%$ das mais velhas, sendo o ramo que mais emprega as meninas de 11 a 15 anos depois da agropecuária e atividades relacionadas.

$5 \quad$ Nas três médias calculadas (para crianças de 5 a 10 anos, 11 a 15 anos e 5 a 15 anos), foram consideradas no cômputo aquelas crianças que não recebem rendimento e excluídas as que não declararam o rendimento. Desconsiderando-se as crianças com rendimento igual a zero, as rendas médias mensal sobem para $R \$ 254,45, R \$ 241,10$ e $R \$ 239,70$ para as faixas de 5 a 10 anos, 11 a 15 anos e 5 a 15 anos, respectivamente.

Consideraram-se apenas as crianças que afirmam receber rendimento zero, desconsiderando-se aquelas que não apresentaram rendimento declarado na PNAD. 
Tabela 1- Percentual de crianças em cada ramo de atividade conforme idade e gênero (2011)

\begin{tabular}{lcccccc}
\hline \multicolumn{1}{c}{$\begin{array}{c}\text { Ramo de } \\
\text { atividade }\end{array}$} & \multicolumn{2}{c}{5 a 10 anos } & \multicolumn{2}{c}{11 a 15 anos } & \multicolumn{2}{c}{5 a 15 anos } \\
Menino & Menina & Menino & Menina & Menino & Menina \\
\hline $\begin{array}{l}\text { Agropecuária, } \\
\text { pesca e }\end{array}$ & $83 \%$ & $66,45 \%$ & $53,41 \%$ & $31,00 \%$ & $56,39 \%$ & $34,07 \%$ \\
$\begin{array}{l}\text { silvicultura } \\
\text { Indústria }\end{array}$ & $3,20 \%$ & $14,77 \%$ & $7,79 \%$ & $8,21 \%$ & $7,33 \%$ & $8,77 \%$ \\
Construção & $1,57 \%$ & $0,00 \%$ & $5,95 \%$ & $0,00 \%$ & $5,51 \%$ & $0,00 \%$ \\
Comércio & $9,12 \%$ & $9,52 \%$ & $19,49 \%$ & $18,23 \%$ & $18,44 \%$ & $17,47 \%$ \\
Serviços & $3,10 \%$ & $3,40 \%$ & $10,03 \%$ & $17,36 \%$ & $9,34 \%$ & $16,15 \%$ \\
$\begin{array}{l}\text { Serviços domés- } \\
\text { ticos }\end{array}$ & $0,00 \%$ & $2,92 \%$ & $0,72 \%$ & $23,43 \%$ & $0,65 \%$ & $21,66 \%$ \\
Outras atividades & $0,00 \%$ & $2,95 \%$ & $2,61 \%$ & $1,77 \%$ & $2,35 \%$ & $1,87 \%$ \\
\hline
\end{tabular}

Fonte: Elaboração própria a partir de dados da PNAD.

A média de horas trabalhadas semanalmente por crianças por grupos de idade e de acordo com o ramo de atividade em que se encontram em 2011 pode ser visualizada na Tabela 2. Pode-se ver que as crianças mais velhas trabalham em média cerca de 9 horas a mais que as crianças mais novas. Para as crianças de 5 a 10 anos, os ramos de atividade que tem maior média de horas trabalhadas por semana é o de serviços e comércio, ao passo que, para as crianças de 11 a 15 anos, serviços domésticos é a atividade que tem maior carga horária de trabalho semanal, 28 horas. A construção civil, embora empregue pequena parcela das crianças, conforme visto na Tabela 1, tem carga horária média de mais de 26 horas para o grupo de 11 a 15 anos, enquanto a carga horária média por semana no comércio está acima de 25 horas. 
Tabela 2 - Média de horas trabalhadas conforme ramo de atividade e grupo etário

\begin{tabular}{lccc}
\hline \multicolumn{1}{c}{ Ramo de atividade } & $\begin{array}{c}\mathbf{5} \text { a 10 } \\
\text { anos }\end{array}$ & $\begin{array}{c}\mathbf{1 1} \text { a 15 } \\
\text { anos }\end{array}$ & $\begin{array}{c}\mathbf{5} \text { a 15 } \\
\text { anos }\end{array}$ \\
\hline $\begin{array}{l}\text { Agropecuária, pesca e silvicul- } \\
\text { tura }\end{array}$ & 12,3 & 19,3 & 18,2 \\
Indústria & 14,9 & 24 & 23,3 \\
Construção & 10,9 & 26,3 & 25,9 \\
Comércio & 16 & 25,2 & 24,7 \\
Serviços & 17 & 22 & 21,8 \\
Serviços domésticos & 10,4 & 28 & 27,8 \\
Outras atividades & 9,5 & 24,1 & 23,6 \\
\hline Média & $\mathbf{1 2 , 9}$ & $\mathbf{2 2 , 2}$ & $\mathbf{2 1 , 3}$ \\
\hline \multicolumn{4}{r}{ Fonte: Elaboração própria a partir de dados da PNAD. }
\end{tabular}

Também é importante analisar o trabalho infantil conforme a situação do domicílio (urbano e rural). Em 2011, das crianças de 5 a 15 anos residentes na área urbana, apenas $2,89 \%$ trabalhavam, contra $12,57 \%$ das residentes em áreas rurais. Entre as crianças de 5 a 10 anos, 0,27\% e 3,61\% trabalhavam nas áreas urbana e rural, respectivamente. No grupo das crianças maiores (11 a 15 anos) a discrepância é maior, apenas 5,59\% das moradoras do perímetro urbano trabalhavam, enquanto $21,81 \%$ das moradoras da zona rural trabalhavam. Na zona rural, também há menos crianças somente estudando, relativamente são 83,5\% das residentes nessa área contra 94,29\% da área urbana, e mais crianças somente trabalhando, $11,80 \%$ versus $2,66 \%$ na área urbana. Da mesma forma, morar na área rural propicia a não realização de "atividade alguma": quase $4 \%$ das crianças do perímetro rural não estudam nem trabalham, enquanto no perímetro urbano são menos de $3 \%$. Por outro lado, na zona rural, a média de horas trabalhadas semanalmente por crianças de 5 a 15 anos é de pouco mais de 18 horas, contra cerca de 24 horas na área urbana. O teste de diferença de média revela que essas médias de horas trabalhadas são estatisticamente diferentes a menos de $1 \%$.

\section{Referencial Metodológico}

O banco de dados para estimação dos modelos econométricos a serem apresentados utilizam apenas as famílias compostas por casal e filhos (considerando também a presença de outros parentes), desconsiderando-se agregados, pensionistas, empregados domésticos e parentes de empregados domésticos. Deve-se ressaltar que na PNAD é possível apenas identificar a mãe do indivíduo quando 
esta reside no mesmo domicílio, mas não o pai. O pai considerado nesse caso é o marido da mãe (chefe do domicílio ou marido do chefe quando este é mulher), podendo ser pai ou padrasto. As variáveis utilizadas nas estimações são apresentadas no Quadro 1 com uma breve descrição.

Quadro 1 - Descrição das variáveis utilizadas no modelo

\begin{tabular}{|l|l|}
\hline \multicolumn{1}{|c|}{ Variável } & \multicolumn{1}{c|}{ Descrição } \\
\hline $\begin{array}{l}\text { Trabalho } \\
\text { (dependente) }\end{array}$ & $\begin{array}{l}\text { Variável binária de status de trabalho do indivíduo que as- } \\
\text { sume valor 1 se o indivíduo trabalha e zero, caso contrário. }\end{array}$ \\
\hline Idade & Idade do indivíduo em anos. \\
\hline Cor & $\begin{array}{l}\text { Variável binária de cor ou raça do indivíduo que assume } \\
\text { valor 1 para brancos e zero, caso contrário. }\end{array}$ \\
\hline Gênero & $\begin{array}{l}\text { Variável binária que assume valor 1 em caso de homens e } \\
\text { zero, caso contrário. }\end{array}$ \\
\hline Idade do pai & Idade do pai em anos. \\
\hline $\begin{array}{l}\text { Escolaridade do } \\
\text { pai }\end{array}$ & Escolaridade do pai em anos. \\
\hline $\begin{array}{l}\text { Idade da mãe } \\
\text { (diferença) }\end{array}$ & Diferença entre a idade do pai e a idade da mãe. \\
\hline $\begin{array}{l}\text { Escolaridade da } \\
\text { mãe }\end{array}$ & Escolaridade da mãe em anos. \\
\hline $\begin{array}{l}\text { Número de } \\
\text { irmãos }\end{array}$ & $\begin{array}{l}\text { Número de outras crianças entre zero e 15 anos existentes } \\
\text { na família (podendo ser irmãos ou outros parentes com } \\
\text { essa faixa etária). }\end{array}$ \\
\hline $\begin{array}{l}\text { Número de } \\
\text { adolescentes }\end{array}$ & $\begin{array}{l}\text { Número de adolescentes de 16 e 17 anos existentes na } \\
\text { família (podendo ser irmãos ou outros parentes com essa } \\
\text { faixa etária). }\end{array}$ \\
\hline $\begin{array}{l}\text { Região } \\
\text { geográfica }\end{array}$ & $\begin{array}{l}\text { Quatro variáveis binárias para as regiões norte, nordeste, } \\
\text { sul e centro-oeste, sendo sudeste a categoria omitida. }\end{array}$ \\
\hline Urbano & $\begin{array}{l}\text { Variável binária que assume valor 1 se o local de residência } \\
\text { é urbano e zero, caso contrário. }\end{array}$ \\
\hline Renda per capita & $\begin{array}{l}\text { Renda per capita proveniente de todas as fontes da família, } \\
\text { exceto a renda proveniente de juros e programas sociais. }\end{array}$ \\
\hline Bolsa Família & $\begin{array}{l}\text { Variável binária que assume valor 1 caso a família tenha } \\
\text { sido identificada como beneficiária do Programa Bolsa } \\
\text { Família e zero, caso contrário. }\end{array}$ \\
\hline
\end{tabular}

$$
\text { Fonte: Elaboração própria. }
$$

Cabe destacar também que não é possível identificar perfeitamente o recebimento do benefício do Programa Bolsa Família pelas famílias. A única variável que 
permite identificar o recebimento do programa é a variável que engloba juros de caderneta de poupança e outras aplicações financeiras, dividendos, programas sociais e outros rendimentos. Em procedimento semelhante ao de Barros, Carvalho e Franco (2007), considerou-se como família participante do programa a que recebesse os valores típicos do Bolsa Família, além de se considerar o corte de renda para ser elegível. Ainda, considerou-se o recebimento do benefício do Bolsa Família combinado com o recebimento do Benefício da Prestação Continuada (BPC). ${ }^{7}$

Embora o Programa Bolsa Família e o BPC se tratem de transferências muito diferentes em termos conceituais e de valores, optou-se por combinar os benefícios para identificar o maior número de beneficiários possível. Assim, pode-se identificar famílias que recebem o Bolsa Família apenas, através da identificação dos valores típicos pagos pelo programa, e também identificar famílias que, embora recebam o BPC, também recebem a transferência do Bolsa Família pela combinação dos valores, uma vez que a família pode ser beneficiada pelos dois programas. Pelo BPC possuir o valor exato de um salário mínimo, torna-se fácil filtrar esse benefício. Quando os valores apresentados na variável "juros de caderneta de poupança e outras aplicações financeiras, dividendos, programas sociais e outros rendimentos" não corresponderam aos valores típicos do Bolsa Família e do Bolsa Família combinado com o BPC, considerou-se como provenientes de juros e outros rendimentos. Assim, a utilização dessa combinação não significa que se está tentando identificar o impacto do BPC sobre o trabalho infantil, mas apenas filtrar a possibilidade da família beneficiária do Bolsa Família também receber o BPC. Esse procedimento segue o proposto por Barros, Carvalho e Franco (2007, p. 50), que indicam que "[...] combinar os benefícios é importante para identificar o maior número de beneficiários".

O método utilizado é o de propensity score matching se a participação no programa Bolsa Família impacta o status de trabalho de crianças. Espera-se que a participação no programa diminua a probabilidade de trabalhar das crianças, uma vez que, tendo que frequentarem a escola, conforme é exigência do programa, as crianças disponham de menos tempo para se dedicar ao trabalho.

Interessa neste estudo medir o impacto de determinado programa (como o Bolsa Família no caso) sobre uma variável de resultado y. Há dois grupos de indivíduos, o grupo dos tratados, isto é, o grupo formado pelos indivíduos que receberam o benefício do programa, e o grupo de controle, ou seja, o grupo formado por indivíduos que não receberam o benefício.

$7 \quad$ O BPC é um benefício garantido pela Constituição Federal e pago desde 1996, cujo valor de um salário mínimo concedido a pessoas com 65 anos ou mais, ou a pessoas com deficiências. $\mathrm{O}$ critério de elegibilidade é a renda familiar per capita inferior a um quarto de salário mínimo (KASSOUF, 2015). Como o valor do benefício é alto em relação a outros benefícios sociais, optou-se por considerar também os valores típicos obtidos com a combinação do recebimento do Bolsa Família e do BPC. Isto é, considerou-se a possibilidade das famílias receberem o benefício da prestação continuada e o Bolsa Família. 
O objetivo dos métodos de avaliação de impacto é construir um grupo de controle adequado, visto que, em geral, em pesquisas sociais não se dispõe de uma amostra aleatória, e estimar os efeitos do programa sobre os beneficiários ou sobre a população como um todo.

O método de propensity score matching compara, para calcular o efeito do tratamento, os resultados obtidos por uma observação que recebeu o tratamento com uma observação que não o recebeu, mas que tem a mesma probabilidade (mesmo escore de propensão) de ter recebido o tratamento que aquela efetivamente tratada. Desse modo, tem-se um procedimento em duas etapas. Primeiro, se calcula, através de um modelo probit ou logit, usualmente, a probabilidade de cada observação ser tratada. Posteriormente, após o devido pareamento entre observações tratadas e não tratadas - o qual pode-se realizar através de diferentes métodos: nearest neighbor matching, radius matching, kernel matching - compara-se o resultado da variável de interesse obtido pelos tratados com o resultado obtido por um ou mais, conforme o método de pareamento, não tratado com similar probabilidade de ser tratado.

Para implementar o pareamento, utiliza-se o software Stata e a rotina "psmatch2", desenvolvida por Leuven e Sianesi (2003).

\section{Resultados e Discussão}

A seguir são apresentados os resultados das estimativas de propensity score matching realizadas para o ano de 2011. Antes, porém, na Tabela 3 são apresentadas as médias e desvios de todas as variáveis utilizadas, separando por grupo de tratamento e de controle e zonas urbana e rural. O primeiro número refere-se à média e o segundo ao desvio padrão.

Tabela 3 - Médias e desvios das variáveis

\begin{tabular}{lcccccc}
\hline \multirow{2}{*}{ Variável } & \multicolumn{2}{c}{ Urbano } & \multicolumn{2}{c}{ Rural } & \multicolumn{2}{c}{ Total } \\
& $\begin{array}{l}\text { Trata- } \\
\text { mento }\end{array}$ & Controle & $\begin{array}{c}\text { Trata- } \\
\text { mento }\end{array}$ & Controle & $\begin{array}{c}\text { Trata- } \\
\text { mento }\end{array}$ & Controle \\
\hline \multirow{2}{*}{ Trabalho } & 0,028 & 0,0301 & 0,1255 & 0,1405 & 0,0731 & 0,0746 \\
& 0,166 & 0,1710 & 0,3314 & 0,3475 & 0,2604 & 0,2628 \\
\hline \multirow{2}{*}{ Idade } & 10,038 & 98,018 & 10,051 & 10,034 & 10,044 & 98,956 \\
& 30,981 & 31,535 & 31,566 & 31,111 & 31,249 & 31,383 \\
\hline \multirow{2}{*}{ Cor } & 0,2640 & 0,2646 & 0,2731 & 0,2101 & 0,2682 & 0,2426 \\
& 0,4409 & 0,4411 & 0,4456 & 0,4075 & 0,4430 & 0,4287 \\
\hline
\end{tabular}


conclusão.

\begin{tabular}{|c|c|c|c|c|c|c|}
\hline \multirow{2}{*}{ Homem } & 0,4962 & 0,5098 & 0,5233 & 0,5170 & 0,5087 & 0,5127 \\
\hline & 0,5000 & 0,4999 & 0,4995 & 0,4998 & 0,4999 & 0,4998 \\
\hline \multirow{2}{*}{$\begin{array}{l}\text { Idade do } \\
\text { pai }\end{array}$} & 39,035 & 39,143 & 40,501 & 41,465 & 39,711 & 40,079 \\
\hline & 95,022 & 10,159 & 93,826 & 94,538 & 94,745 & 99,457 \\
\hline \multirow{2}{*}{$\begin{array}{l}\text { Escolarida- } \\
\text { de pai }\end{array}$} & 42,636 & 49,620 & 25,574 & 24,543 & 34,768 & 39,509 \\
\hline & 37,152 & 40,187 & 30,806 & 29,348 & 35,405 & 38,240 \\
\hline \multirow{2}{*}{$\begin{array}{l}\text { Diferença } \\
\text { idade mãe }\end{array}$} & 41,250 & 41,544 & 47,058 & 58,004 & 43,928 & 48,181 \\
\hline & 73,339 & 80,457 & 64,958 & 75,271 & 69,653 & 78,816 \\
\hline \multirow{2}{*}{$\begin{array}{l}\text { Escolarida- } \\
\text { de mãe }\end{array}$} & 51,721 & 52,701 & 38,174 & 32,306 & 45,474 & 44,478 \\
\hline & 38,286 & 39,483 & 32,356 & 32,964 & 36,304 & 38,320 \\
\hline \multirow{2}{*}{$\begin{array}{l}\text { Número } \\
\text { de irmãos }\end{array}$} & 16,088 & 24,541 & 16,111 & 29,451 & 16,099 & 26,521 \\
\hline & 1,091 & 15,540 & 11,169 & 17,644 & 11,029 & 16,595 \\
\hline \multirow{2}{*}{$\begin{array}{l}\text { Número } \\
\text { de adoles- } \\
\text { centes }\end{array}$} & 0,1909 & 0,1990 & 0,2511 & 0,2761 & 0,2187 & 0,2300 \\
\hline & 0,4337 & 0,4293 & 0,4932 & 0,5097 & 0,4630 & 0,4649 \\
\hline \multirow{2}{*}{ Norte } & 0,1905 & 0,2842 & 0,2012 & 0,3342 & 0,1954 & 0,3044 \\
\hline & 0,3928 & 0,4511 & 0,4010 & 0,4718 & 0,3966 & 0,4602 \\
\hline \multirow{2}{*}{ Nordeste } & 0,6040 & 0,4121 & 0,6652 & 0,5088 & 0,6322 & 0,4511 \\
\hline & 0,4891 & 0,4922 & 0,4720 & 0,5000 & 0,4822 & 0,4976 \\
\hline \multirow{2}{*}{ Sul } & 0,0495 & 0,0689 & 0,0387 & 0,0434 & 0,0445 & 0,0586 \\
\hline & 0,2170 & 0,2533 & 0,1930 & 0,2038 & 0,2063 & 0,2349 \\
\hline \multirow{2}{*}{ Sudeste } & 0,1110 & 0,1749 & 0,0704 & 0,0807 & 0,0923 & 0,1369 \\
\hline & 0,3142 & 0,3799 & 0,2560 & 0,2724 & 0,2895 & 0,3438 \\
\hline \multirow{2}{*}{$\begin{array}{l}\text { Centro- } \\
\text {-oeste }\end{array}$} & 0,0443 & 0,0459 & 0,0219 & 0,0278 & 0,0340 & 0,0386 \\
\hline & 0,2059 & 0,2093 & 0,1465 & 0,1645 & 0,1812 & 0,1927 \\
\hline \multirow{2}{*}{$\begin{array}{l}\text { Distrito } \\
\text { Federal } \\
\end{array}$} & 0,0003 & 0,0138 & 0,0023 & 0,0049 & 0,0012 & 0,0102 \\
\hline & 0,0199 & 0,1168 & 0,0482 & 0,0699 & 0,0359 & 0,1006 \\
\hline \multirow{2}{*}{ Urbano } & - & - & - & - & 0,5388 & 0,5967 \\
\hline & - & - & - & - & 0,4985 & 0,4905 \\
\hline \multirow{2}{*}{$\begin{array}{l}\text { Renda per } \\
\text { capita }\end{array}$} & 85,832 & 91,441 & 69,890 & 78,071 & 78,481 & 86,050 \\
\hline & 46,022 & 42,282 & 43,912 & 37,661 & 45,752 & 41,007 \\
\hline $\begin{array}{l}\text { Número } \\
\text { de obser- } \\
\text { vações }\end{array}$ & 2.503 & 3.613 & 2.142 & 2.441 & 4.645 & 6.054 \\
\hline
\end{tabular}

Fonte: Elaboração própria a partir de dados da pesquisa. 
Optou-se por apresentar os resultados dos modelos que consideram apenas a amostra formada por famílias que tem renda mensal familiar per capita de R\$ 140,00 porque são essas as famílias que atendem ao critério de renda para ser elegível a participar do programa. As estimativas para outros cortes de renda, ou sem nenhum corte de renda, não se revelaram melhores, sendo mais difícil conseguir o balanceamento das covariadas nesses casos. Ao se construir a amostra apenas com aquelas pessoas que efetivamente atendem ao critério de renda para recebimento do Bolsa Família, se trabalhou com um grupo muito mais homogêneo em relação às demais características. Além disso, se considerou o impacto do programa para as famílias que efetivamente são o público-alvo do programa.

Os resultados para o modelo logit que calcula a probabilidade de participar do programa para o ano de 2011 encontram-se na Tabela 4. É através dessa probabilidade que se realiza o pareamento entre as observações. Encontra-se para cada observação tratada um (ou mais de um, conforme o tipo de pareamento) "par" no grupo de controle que tenha a mesma probabilidade estimada de participação do programa. Assim, comparam-se observações que difiram apenas no fato de que uma recebe o benefício e outra não, sendo, sob todos os outros aspectos, idênticas. Esses aspectos apresentam informação "resumida" no valor da probabilidade estimada de participação do programa.

Tabela 4 - Resultados do modelo logit que estima a probabilidade de participação do programa

\begin{tabular}{llll}
\hline \multicolumn{1}{c}{ Variável } & \multicolumn{3}{c}{ Coeficiente } \\
\hline Idade & \multicolumn{1}{c}{$(\mathbf{1})$} & $\mathbf{( 2 )}$ & (3) \\
Cor & $0,0119698 * *$ & $0,0259973 *$ & $-0,0081501$ \\
Homem & 0,0646528 & $-0,0226244$ & $0,2050332 *$ \\
Idade do pai & $-0,0448878$ & $-0,095883 * * *$ & 0,0209312 \\
Educação do pai & $-0,0152591 *$ & $-0,0205226 *$ & $-0,005137$ \\
Diferença de idade entre pai & $0,0071757 * *$ & $0,0204369 *$ & $-0,0152013 * *$ \\
e mãe & $-0,0468624 *$ & $-0,0589303 *$ & $-0,0102031$ \\
Educação da mãe & $-0,0032891$ & $-0,0162994 * *$ & $0,0277771 * *$ \\
Número de irmãos & $-0,5639257 *$ & $-0,4967066 *$ & $-0,6511838 *$ \\
Número de adolescentes na & $-0,0186903$ & $-0,0706308$ & 0,0467035 \\
família & & & \\
Norte & $0,1371756 * *$ & $0,1616778 * *$ & 0,0503402 \\
Nordeste & $0,6758518 *$ & $0,6933605 *$ & $0,6435665 *$ \\
Sul & 0,1380631 & 0,2055292 & $-0,190407$ \\
\hline
\end{tabular}


conclusão.

\begin{tabular}{llll}
\hline Centro-oeste & $0,2818138^{* * *}$ & $0,3342737^{* *}$ & 0,0869278 \\
Distrito Federal & $-1,832081^{*}$ & $-3,351347^{*}$ & $-0,3246282$ \\
Urbano & $-0,2323582^{*}$ &.. & $\ldots$ \\
Constante & $1,28217^{*}$ & $1,102533^{*}$ & $1,139768^{*}$ \\
Número de observações & 10.699 & 6.116 & 4.583 \\
\hline
\end{tabular}

Fonte: Elaboração própria a partir dos dados da pesquisa.

Nota: * Significativo a 1\%; "* significativo a 5\%; *** significativo a 10\%.

Na Tabela 4, encontram-se os coeficientes estimados das variáveis para três equações distintas: 1) considerando todas as crianças, independente da área de residência; 2) considerando apenas as crianças residentes na zona urbana; 3) considerando apenas as crianças residentes na zona rural.

A Tabela 5 mostra os resultados do impacto do Programa Bolsa Família sobre a variável de trabalho para toda a amostra e para as zonas urbana e rural separadas. Optou-se por estimar o impacto também separadamente para os residentes nos meios urbano e rural para garantir melhor balanceamento da variável urbano (a binária indicativa de zona de residência). Utilizaram-se quarto tipos de matching: nearest neighbor matching, radius matching, kernel matching e mahalanobis.

Tabela 5 - Resultados das estimativas de propensity score matching para a variável binária de trabalho

\begin{tabular}{l|llll}
\hline \multicolumn{1}{c|}{ Variável } & $\begin{array}{l}\text { Nearest } \\
\text { neighbor } \\
\text { matching }\end{array}$ & $\begin{array}{l}\text { Radius } \\
\text { matching }\end{array}$ & $\begin{array}{l}\text { Kernel } \\
\text { matching }\end{array}$ & Mahalanobis \\
\hline Crianças & & & & \\
Impacto & $-0,002368648$ & 0,000295923 & 0,000156057 & $-0,003875135$ \\
Erro padrão & 0,007592524 & 0,00570591 & 0,005693342 & 0,007448354 \\
Teste t & $-0,31$ & 0,05 & 0,03 & $-0,52$ \\
\hline Crianças urbano & & & & \\
Impacto & $-0,003598561$ & $-0,003122778$ & $-0,00300743$ & $-0,004394726$ \\
Erro padrão & 0,006566894 & 0,004778746 & 0,004769879 & 0,00631877 \\
Teste t & $-0,55$ & $-0,65$ & $-0,63$ & $-0,70$ \\
\hline Crianças rural & & & & \\
Impacto & 0 & $-0,001504782$ & $-0,001984072$ & $-0,002334267$ \\
Erro padrão & 0,015282638 & 0,011935089 & 0,011868171 & 0,014752884 \\
Teste t & 0,00 & $-0,13$ & $-0,17$ & $-0,16$ \\
\hline
\end{tabular}

Fonte: Elaboração própria a partir de dados da pesquisa. 
Nenhum dos resultados do impacto do programa Bolsa Família sobre a variável binária de trabalho é estatisticamente significativo, de modo que não é possível afirmar que o programa tenha impacto sobre o trabalho infantil. Embora não significativo, o sinal é negativo para a maioria dos resultados, sinalizando no sentido de que o programa reduziria a probabilidade de a criança trabalhar.

$\mathrm{Na}$ tabela 6 são reportados os resultados do impacto do programa Bolsa Família sobre as horas trabalhadas semanalmente. Novamente, para nenhum dos quatro tipos de matching tem-se resultados estatisticamente significativos. O sinal é negativo para a maioria dos resultados.

Tabela 6 - Resultados das estimativas de propensity score matching para a variável horas trabalhadas

\begin{tabular}{|c|c|c|c|c|}
\hline \multirow[b]{2}{*}{ Variável } & \multicolumn{4}{|c|}{ Estimador } \\
\hline & $\begin{array}{l}\text { Nearest } \\
\text { neighbor } \\
\text { matching }\end{array}$ & $\begin{array}{l}\text { Radius } \\
\text { matching }\end{array}$ & $\begin{array}{l}\text { Kernel } \\
\text { matching }\end{array}$ & Mahalanobis \\
\hline \multicolumn{5}{|l|}{ Crianças } \\
\hline Impacto & $-0,049956934$ & $-0,043232597$ & $-0,044387012$ & 0,02411194 \\
\hline Erro padrão & 0,160558611 & 0,125306782 & 0,125017629 & 0,15646566 \\
\hline Teste $\mathrm{t}$ & $-0,31$ & $-0,35$ & $-0,36$ & 0,15 \\
\hline \multicolumn{5}{|l|}{$\begin{array}{l}\text { Crianças } \\
\text { urbano }\end{array}$} \\
\hline Impacto & $-0,031587365$ & $-0,11154609$ & $-0,107305316$ & $-0,04394726$ \\
\hline Erro padrão & 0,160112908 & 0,124740122 & 0,124488947 & 0,14678382 \\
\hline Teste $\mathrm{t}$ & $-0,20$ & $-0,89$ & $-0,86$ & $-0,30$ \\
\hline \multicolumn{5}{|l|}{ Crianças rural } \\
\hline Impacto & $-0,133426966$ & $-0,10455688$ & $-0,093264648$ & 0,19234360 \\
\hline Erro padrão & 0,326435275 & 0,246793059 & 0,245384281 & 0,29412893 \\
\hline Teste $\mathrm{t}$ & $-0,41$ & $-0,42$ & $-0,38$ & 0,65 \\
\hline
\end{tabular}

Fonte: Elaboração própria a partir de dados da pesquisa.

A Tabela 7 apresenta os resultados do teste de balanceamento para o nearest neighbor matching considerando a amostra formada por todas as crianças. Quase todas as variáveis de controle estão balanceadas, isto é, são estatisticamente iguais para os grupos de controle e de tratamento. As exceções são as binárias das regiões nordeste e sul, a binária urbano (por isso a opção por se realizar também as estimativas separando urbano e rural) e a renda per capita. 
Tabela 7-Resultados do teste de balanceamento para o nearest neighbor matching

\begin{tabular}{l|cccc}
\hline \multirow{2}{*}{ Variável } & \multicolumn{2}{|c}{ Média } & \multicolumn{2}{c}{ Teste $\boldsymbol{t}$} \\
\cline { 2 - 5 } & Tratamento & Controle & $\mathbf{T}$ & $\mathbf{p}>|\mathbf{t}|$ \\
\hline Idade & 10,046 & 9,9668 & 1,20 & 0,229 \\
Cor & 0,26809 & 0,26916 & $-0,12$ & 0,907 \\
Homem & 0,50883 & 0,5168 & $-0,77$ & 0,442 \\
Idade do pai & 39,716 & 39,755 & $-0,19$ & 0,848 \\
Educação do pai & 3,4776 & 3,5233 & $-0,61$ & 0,543 \\
Diferença de idade entre & 4,3936 & 4,4242 & $-0,20$ & 0,842 \\
pai e mãe & 4,5478 & 4,5917 & $-0,55$ & 0,580 \\
Educação da mãe & 1,6102 & 1,5646 & 1,89 & 0,058 \\
Número de irmãos & 0,21878 & 0,21813 & 0,07 & 0,946 \\
Número de adolescentes & 0,19552 & 0,20693 & $-1,37$ & 0,170 \\
na família & 0,63221 & 0,60487 & 2,71 & 0,007 \\
Norte & 0,04457 & 0,05469 & $-2,25$ & 0,025 \\
Nordeste & 0,09238 & 0,09776 & $-0,88$ & 0,377 \\
Sul & 0,03402 & 0,03445 & $-0,11$ & 0,909 \\
Sudeste & 0,00129 & 0,00129 & $-0,00$ & 1,000 \\
Centro-oeste & 0,53898 & 0,56675 & $-2,69$ & 0,007 \\
Distrito Federal & 78,498 & 86,406 & $-8,55$ & 0,000 \\
Urbano & & & & \\
Renda per capita & & & & \\
\hline
\end{tabular}

Fonte: Elaboração própria a partir de dados da pesquisa.

Quanto ao fato de os resultados serem não significativos, salienta-se o argumento apresentado por Cacciamali, Tatei e Batista (2010) e Araújo, Ribeiro e Neder (2010) de que a redução no trabalho infantil não é objetivo do programa, além do fato de que os beneficiários são famílias muito pobres que precisam do rendimento proveniente do trabalho infantil. Outra justificativa para a falta de impacto do programa no sentido de reduzir o trabalho infantil é fornecida por Basu e Tzannatos (2003), os quais afirmam que o acréscimo de renda para pessoas pobres pode possibilitar que adquiram terra ou abram um negócio, criando um ambiente mais propício para o emprego da mão de obra infantil.

Outro ponto que pode ser ressaltado é o discutido por Fors (2012), que considera positiva a existência de programas de transferência de renda como formas de aliviar o trabalho infantil, mas argumenta que, em casos de países que têm nível de renda per capita baixo, a transferência de renda pode não funcionar. A autora 
acrescenta que nesses casos o crescimento econômico é uma alternativa que, no entanto, alivia o trabalho infantil apenas a longo prazo ao melhorar o padrão de vida dos habitantes (FORS, 2012).

As famílias escolhem manter suas crianças trabalhando porque precisam da complementação de renda fornecida pelo salário do infante ou porque essa é a melhor alternativa entre aquelas disponíveis para o tempo disponível das crianças (EDMONDS; PAVCNIK, 2005). Ferro e Kassouf (2005) argumentam que a renda (ou mais especificamente a pobreza) não é necessariamente o fator predominante na decisão de enviar as crianças ao trabalho, pois também influenciam nessa decisão fatores culturais, a percepção do trabalho como educativo e o fato da educação formal oferecida não ser considerada adequada. Assim, a transferência de renda não basta, muitas vezes, para a retirada da criança do trabalho pelas famílias porque o trabalho não é, necessariamente, visto como negativo ou prejudicial.

Marin et al. (2012) analisam o trabalho infantil na produção de tabaco através de um estudo de caso em Agudo (RS) por meio de entrevistas com agricultores familiares fumicultores com filhos menores de 18 anos. Os autores revelam que a presença do trabalho infantil no meio agrícola é vista como forma de inclusão social, de ajuda ao sustento familiar e de ensino das técnicas necessárias para a continuidade da produção e reprodução daquele modo de vida. A concepção dos pais é de que os filhos pequenos são mais poupados do trabalho, desfrutando de maior liberdade e tempo livre, do que eles próprios quando eram crianças (MARIN et al., 2012). O entendimento dos pais é de que o trabalho é não apenas uma forma de socialização, mas a preparação para a vida, cabendo aos pais "ensinar a trabalhar", sendo o trabalho um valor a ser transmitido aos filhos.

A ideia do "ensinar a trabalhar" apresentada na pesquisa de Marin et al. (2012) é corroborada por Basu e Tzannatos (2003). Estes autores afirmam que, para aqueles que vivem em situação precária, é melhor que os filhos aprendam o oficio do pai do que ir para a escola e não aprender nada que seja considerado útil para o mercado de trabalho.

Assim, a escola não é sempre considerada pelas famílias como espaço suficiente para o bom desenvolvimento da criança, pois veem somente no trabalho uma preparação necessária para a vida adulta que apenas ele pode fornecer. Igualmente, a falta de outro espaço-tempo alternativo ao trabalho torna essa opção vista como mais adequada para o tempo livre da criança.

Giovanni (2002) apresenta o perfil das crianças que trabalham nas ruas do município de Campinas e identifica que o principal motivo para o trabalho de menores de 16 anos são, segundo os responsáveis pelas crianças, a necessidade de ajudar nas despesas familiares e a possibilidade da criança ter seu próprio dinheiro. O trabalho também assume papel disciplinador, serve para que as crianças não fiquem na rua à toa, roubando ou sujeitas ao consumo de drogas. Assim, de 
acordo com Giovanni (2002, p. 80), existe “[...] a concepção do trabalho como um valor e como uma forma de proteger os filhos do ambiente em que vivem nos bairros de periferia e em favelas, desprovidos de alternativas de lazer e de atividades formativas".

Diante dessa discussão, em muitos casos a percepção do trabalho na infância como algo negativo não está presente. Torna-se necessário medir a percepção familiar do trabalho infantil como algo positivo, negativo ou neutro para o desenvolvimento da criança. Essa percepção, que muito pode influenciar na decisão de enviar a criança ao trabalho ou não (independente da necessidade da complementação de renda), pode representar uma variável omitida, viesando os resultados deste estudo a respeito do impacto do programa sobre o trabalho infantil.

A última tentativa de encontrar resultados significativos foi estimar um modelo logit da variável binária de trabalho e uma regressão das horas trabalhadas, tendo como variável explicativa a renda oriunda da transferência do programa, ao invés da binária indicativa de participação. Fazendo isso, se espera que o aumento de renda proveniente das transferências reduza a probabilidade de a criança trabalhar e/ou o número de horas trabalhadas. Na Tabela 8 encontram-se os resultados para três equações distintas: 1) considerando todas as crianças, independente do área de residência; 2) considerando apenas as crianças residentes na zona urbana; 3) considerando apenas as crianças residentes na zona rural. Cabe ressaltar que os resultados consideram a amostra da PNAD expandida.

Tabela 8 - Resultados do modelo logit da binária de trabalho usando a variável renda do programa

\begin{tabular}{|c|c|c|c|}
\hline \multirow{2}{*}{ Variável } & \multicolumn{3}{|c|}{$d y / d x$} \\
\hline & (1) & (2) & (3) \\
\hline Renda do programa & $-4.92 \mathrm{e}-07$ & $-0,0000118 *$ & $2.57 \mathrm{e}-06$ \\
\hline Idade & $0,0241177^{*}$ & $0,0145513^{*}$ & $0,037018 *$ \\
\hline Cor & $-0,0114239^{*}$ & $-0,0092217^{*}$ & $-0,0130273^{*}$ \\
\hline Homem & $0,0595475^{*}$ & $0,023164 *$ & $0,102603^{*}$ \\
\hline Idade do pai & $0,0004838 *$ & $0,000634^{*}$ & $0,0002514^{*}$ \\
\hline Educação do pai & $-0,0021576^{*}$ & $-0,0005424^{*}$ & $-0,004554^{*}$ \\
\hline $\begin{array}{l}\text { Diferença de idade entre pai } \\
\text { e mãe }\end{array}$ & $0,0000614^{*}$ & $-0,0001303 *$ & $0,0002735^{*}$ \\
\hline Educação da mãe & $-0,0013665^{*}$ & $-0,001063^{*}$ & $-0,0013879$ \\
\hline Número de irmãos & $0,0052747^{*}$ & $0,0043832 *$ & $0,0072236 *$ \\
\hline $\begin{array}{l}\text { Número de adolescentes na } \\
\text { família }\end{array}$ & $0,005117^{*}$ & $0,00045 * *$ & $0,0120217^{*}$ \\
\hline
\end{tabular}

continua... 
conclusão.

\begin{tabular}{lccc}
\hline Norte & $0,0363515^{*}$ & $0,0282569^{*}$ & $0,0332264^{*}$ \\
Nordeste & $0,01944^{*}$ & $0,0272618^{*}$ & $-0,0010284$ \\
Sul & $0,0242144^{*}$ & $0,019808^{*}$ & $0,0179201^{*}$ \\
Centro-oeste & $-0,0296739^{*}$ & $-0,0030712^{*}$ & $-0,0690732^{*}$ \\
Urbano & $-0,0831633^{*}$ &.. &.. \\
Renda per capita & $-0,0000788^{*}$ & $0,0000228^{*}$ & $-0,0002451^{*}$ \\
Constante & $0,0754172^{*}$ & $0,0303737^{*}$ & $0,1290761^{*}$ \\
Número de observações & 5.607 .168 & 3.048 .298 & 2.558 .870 \\
\hline
\end{tabular}

Fonte: Elaboração própria a partir de dados da pesquisa.

Nota: * Significativo a 1\%; ** significativo a 5\%; ** significativo a $10 \%$.

Os valores apresentados na Tabela 8 são dos efeitos marginais. Embora significativo, o impacto da renda de benefícios sociais sobre a probabilidade de a criança trabalhar é muito pequeno, não chegando a $1 \%$.

A Tabela 9 mostra os resultados da regressão das horas trabalhadas usando a variável renda recebida do programa. Vale lembrar que nas regressões das horas trabalhadas estão incluídas apenas as crianças que trabalham, pois, caso fossem estimadas usando todas as observações, haveria o problema de variável truncada, visto que horas trabalhadas somente são observadas para as crianças que trabalham. 
Tabela 9 - Resultados da regressão das horas trabalhadas usando a variável renda do programa

Variável

\begin{tabular}{lccc}
\hline \multicolumn{1}{c}{ Variável } & \multicolumn{3}{c}{ Coeficientes } \\
& $\mathbf{( 1 )}$ & $\mathbf{( 2 )}$ & $\mathbf{( 3 )}$ \\
\hline Renda do programa & $-0,0070197^{*}$ & $-0,0132717^{*}$ & $-0,0070668^{*}$ \\
Idade & $1,503059^{*}$ & $2,821502^{*}$ & $1,279238^{*}$ \\
Cor & $-0,5673029^{*}$ & $-0,7850748^{*}$ & $-0,8644593^{*}$ \\
Homem & $3,201948^{*}$ & $3,185538^{*}$ & $3,273544^{*}$ \\
Idade do pai & $0,0219994^{*}$ & $-0,2323116^{*}$ & $0,1111875^{*}$ \\
Educação do pai & $-0,0293027^{*}$ & $-0,3003254^{*}$ & $0,1884592^{*}$ \\
Diferença de idade entre pai & $-0,1800628^{*}$ & $-0,1921866^{*}$ & $-0,1964288^{*}$ \\
e mãe & $-0,0138915^{* *}$ & $-0,0808693^{*}$ & $0,0283718^{*}$ \\
Educação da mãe & $0,2340097^{*}$ & $0,5924393^{*}$ & $0,2359414^{*}$ \\
Número de irmãos & $0,5417608^{*}$ & $3,712507^{*}$ & $-0,7311083^{*}$ \\
Número de adolescentes na & & \\
família & $0,6546185^{*}$ & $10,32359^{*}$ & $-1,94048^{*}$ \\
Norte & $0,7120943^{*}$ & $3,386426^{*}$ & $0,1773284^{*}$ \\
Nordeste & $0,9590478^{*}$ & $13,02128^{*}$ & $-3,198089^{*}$ \\
Sul & $5,681191^{*}$ & $21,2359^{*}$ & $-3,245575^{*}$ \\
Centro-oeste & $2,678563^{*}$ & $\ldots$ & $\ldots$ \\
Urbano & $-0,027369^{*}$ & $-0,055454^{*}$ & $-0,0139196^{*}$ \\
Renda per capita & $-2,035224^{*}$ & $-8,079347^{*}$ & $-2,853804^{*}$ \\
Constante & 422.877 & 92.588 & 330.289 \\
Número de observações & & & \\
\hline
\end{tabular}

Fonte: Elaboração própria.

Todas as variáveis de controle são significativas para explicar o número de horas trabalhadas por crianças que trabalham, então apresentam o sinal esperado. Apresentam-se negativas, isto é, reduzem o número de horas trabalhadas: a diferença entre idade do pai e da mãe e a renda familiar per capita. Ainda verificou-se que crianças brancas (valor 1 da variável binária cor) trabalham menos horas que crianças pretas e pardas e que meninos trabalham mais que meninas. O sinal dos coeficientes das variáveis de anos de estudo de pais e mães são negativos quando se considera a equação 1 de todas as crianças e a equação 2 das crianças urbanas, indicando que, quanto maior o nível de escolaridade dos pais, menos horas a criança trabalha. Para crianças da zona rural, as variáveis de escolaridade dos pais 
têm sinal positivo. Possivelmente, na zona rural existem muito mais fatores influenciando a decisão da criança trabalhar e o número de horas dedicadas ao trabalho do que na zona urbana. Crianças do nordeste e crianças urbanas do norte, sul e centro-oeste trabalham mais horas, em média, que crianças do sudeste (categoria adotada como base), enquanto crianças do norte, sul e centro-oeste rural trabalham menos. A variável de interesse, a renda recebida de transferências sociais, tem sinal negativo e significativo nas três equações, indicando que quanto maior a renda recebida, menos horas a criança trabalha. Desse modo, apesar de este estudo não ter encontrado impacto da participação no programa sobre o trabalho infantil estatisticamente significativo, o aumento do valor da transferência causa impacto para reduzir a probabilidade de a criança trabalhar, bem como o número de horas trabalhadas.

Os resultados não significativos encontrados e a discussão ao longo de todo este trabalho apontam principalmente para a necessidade de dados mais precisos no que se refere ao recebimento do benefício do Bolsa Família. A existência de uma variável específica para a participação no programa em uma pesquisa do vulto da PNAD em um ano mais recente permitiria que pesquisadores realizassem estimativas mais confiáveis sobre o real impacto do programa, não apenas sobre o trabalho infantil, mas também sobre outros temas de grande importância social. Assim, estimativas do impacto do programa depois de um prazo relativamente longo de sua existência permitiria também comparações desses resultados com aqueles já realizados utilizando os dados de anos que disponibilizaram uma pergunta sobre a participação no programa.

\section{Considerações Finais}

Este trabalho teve como problema de pesquisa avaliar o impacto do programa de transferência condicional de renda Bolsa Família sobre o status de trabalho de crianças de 5 a 15 anos, usando os dados da PNAD de 2011 e o método de propensity score matching. Esperava-se que o programa Bolsa Família apresentasse como efeito transbordamento uma redução no trabalho infantil, visto que, ao apresentar como condicionalidade a frequência escolar, reduzisse o tempo disponível da criança, bem como representasse um complemento de renda familiar e substituto para a renda da criança.

A principal limitação do presente estudo está na dificuldade de identificar com precisão absoluta os beneficiários do programa Bolsa Família, uma vez que não existe nas PNADs recentes uma pergunta específica para a participação no programa. Acredita-se que, com maior precisão na identificação dos beneficiários, seria possível uma avaliação de impacto do programa mais acurada. Para se realizar as estimativas com os dados disponíveis, considerou-se como beneficiárias do 
programa as famílias que declararam na questão sobre rendimentos provenientes de programas sociais e outros rendimentos receber uma das quantias pagas pelo Bolsa Família, conforme número de filhos e renda familiar. Sugere-se fortemente a inclusão de questões específicas sobre a participação em programas sociais no questionário da PNAD, o que permitiria melhores avaliações de impacto desses programas.

Também se estimaram, considerando a amostra expandida da PNAD, um modelo logit da probabilidade de a criança trabalhar em função da renda de transferência social recebida e de variáveis de controle e uma regressão do número de horas trabalhadas em função da renda de transferência social e dos controles. No modelo logit, que estima a probabilidade de a criança trabalhar, o coeficiente da renda de transferência social apresentou sinal negativo e significativo para crianças da zona urbana, conforme o esperado, indicando que quando a renda de transferência aumenta, a probabilidade de a criança com domicílio urbano trabalhar diminui. Na regressão do número de horas trabalhadas, o sinal do coeficiente da variável da renda de transferência foi negativo e significativo tanto para crianças da área urbana, quanto da área rural. Portanto, embora não se tenha encontrado impacto significativo da participação no programa Bolsa Família sobre o trabalho infantil, o valor da transferência apresentou impacto negativo e significativo sobre as variáveis de interesse.

Outra sugestão decorrente da reflexão e análise dos resultados é a inclusão de uma pergunta sobre a percepção do trabalho infantil como algo positivo, negativo ou neutro pela família, bem como sobre a percepção da escola como a melhor alternativa ao trabalho para o correto desenvolvimento da criança.

\section{Referências}

ARAÚJO, G. S.; RIBEIRO, R.; NEDER, H. D. Impactos do Programa Bolsa Família sobre o trabalho de crianças e adolescentes residentes na área urbana. Economia, Brasília, DF, v. 11, n. 4, p. 57-102, dez. 2010.

BARROS, R. P., MENDONÇA, R. S. P. Trabalho infantil no Brasil: rumo à erradicação. Sinais Sociais, Rio de Janeiro, v. 5, n. 17, p. 142-173, set./dez. 2011.

BARROS, R. P.; CARVALHO, M.; FRANCO, S. O papel das transferências públicas na queda recente da desigualdade de renda brasileira. In: BARROS, R. P.; FOGUEL, M. N.; ULYSSEA, G. Desigualdade de renda no Brasil: uma análise da queda recente. Brasília: Instituto de Pesquisa Econômica Aplicada, 2007. v. 2. p. 41-86.

BASU, K. Child Labor: Cause, consequence and cure, with remarks on international labor standards. Journal of Economic Literature, Pittsburgh, v. 37, p. 1083-1119, Sept. 1999.

BASU, K.; TZANNATOS, Z. The global child labor problem: what do we know and what can we do? The World Bank Economic Review, New York, v. 17, n. 2, p. 147-173, 2003. 
BRASIL. Decreto n. 5.209 de 17 de setembro de 2004. Regulamenta a Lei $n^{\circ} 10.836$, de 9 de janeiro de 2004, que cria o Programa Bolsa Família, e dá outras providências. Disponível em: <http://www.planalto.gov.br/ccivil_03/_ato2004-2006/2004/decreto/d5209.htm>. Acesso em: 10 abr. 2013a.

Lei $n^{0} 10.836$ de 9 de janeiro de 2004. Cria o Programa Bolsa Família e dá outras providências. Disponível em: < http://www.planalto.gov.br/ccivil_03/_ato2004-2006/2004/ lei/110.836.htm > . Acesso em: 10 abr. 2013b.

CACCIAMALI, M. C.; TATEI, F.; BATISTA, N. F. Impactos do programa bolsa família federal sobre o trabalho infantil e a freqüência escolar. Revista Economia Contemporânea, Rio de Janeiro, v. 14, n. 2, p. 269-301, maio/ago. 2010.

CARDOSO, E.; SOUZA, A. P. The impact of cash transfers on child and school attendance in Brazil. Nashville: Department of Economics Vanderbilt University, 2004. 52p. (Vanderbilt University Working Paper, n. 04-W07). Disponível em: <http://www.vanderbilt.edu/econ/ wparchive/workpaper/vu04-w07.pdf>. Acesso em: 05 nov. 2012.

DUTRA, M. União repassou quase R $\$ 25$ bilhões aos beneficiários do Bolsa Família em 2013. In: Contas Abertas, 22 jan. 2014. Disponível em: < http://www.contasabertas.com.br/website/ arquivos/7603> Acesso em: 21 jul. 2015.

EDMONDS, E. V.; PAVCNIK, N. Child labor in the global economy. The Journal of Economic Perspectives, Nashville, v. 19, n. 1, p. 199-220, 2005.

FERRO, A. R.; KASSOUF, A. L. Avaliação do impacto dos programas Bolsa Escola sobre o trabalho infantil no Brasil. Pesquisa e Planejamento Econômico, Rio de Janeiro,v. 35, n. 3, p. 417-444, 2005.

FERRO, A. R.; KASSOUF, A. L.; LEVISON, D. The impact of conditional cash transfer programs on household work decisions in Brazil. Research in Labor Economics, Bingley, v. 31, p. 193-218. 2010.

FORS, H. C. Child labour: a review of recent theory and evidence with policy implications. Journal of Economic Surveys, Oxford, v. 26, n. 4, p. 570-594, 2012.

FUNDO DAS NAÇÕES UNIDAS PARA A INFÂNCIA. Child labour. Disponível em: < http:// www.unicef.org/protection/57929_58009.html>. Acesso em: 26 nov. 2012.

GIOVANNI, G. (Org.). Trabalho infantil em Campinas. Campinas: Unicamp, 2002.

IBGE. Pesquisa por Amostra de Domicílios: 1992. Rio de Janeiro: IBGE, 1994.

. Pesquisa por Amostra de Domicílios: 1993. Rio de Janeiro: IBGE, 1995.

. Pesquisa por Amostra de Domicílios: 1995. Rio de Janeiro: IBGE, 1997.

. Pesquisa por Amostra de Domicílios: 1998. Rio de Janeiro: IBGE, 2000.

. Pesquisa por Amostra de Domicílios: 1999. Rio de Janeiro: IBGE, 2001.

. Pesquisa por Amostra de Domicílios: 2001. Rio de Janeiro: IBGE, 2003. 
. Pesquisa por Amostra de Domicílios: 2002. Rio de Janeiro: IBGE, 2004.

. Pesquisa por Amostra de Domicílios: 2003. Rio de Janeiro: IBGE, 2005.

. Pesquisa por Amostra de Domicílios: 2004. Rio de Janeiro: IBGE, 2006.

. Pesquisa por Amostra de Domicílios: 2005. Rio de Janeiro: IBGE, 2007.

. Pesquisa por Amostra de Domicílios: 2006. Rio de Janeiro: IBGE, 2008.

. Pesquisa por Amostra de Domicílios: 2007. Rio de Janeiro: IBGE, 2009.

. Pesquisa por Amostra de Domicílios: 2008. Rio de Janeiro: IBGE, 2010.

. Pesquisa por Amostra de Domicílios: 2009. Rio de Janeiro: IBGE, 2011.

KASSOUF, A. L. Evolução do trabalho infantil no Brasil. Sinais Sociais, Rio de Janeiro, v. 9, n. 27, p. 9-45, jan./abr. 2015.

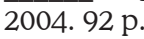

. O perfil do trabalho infantil no Brasil, por regiões e ramos de atividade. Brasília: OIT,

. O que conhecemos sobre o trabalho infantil? Nova Economia, Belo Horizonte, v. 17, n. 2, p. 323-350, maio/ago. 2007.

LEUVEN, E.; SIANESI, B. PSMATCH2: Stata module to perform full Mahalanobis and propensity score matching, common support graphing, and covariate imbalance testing. Disponível em: <http://ideas.repec.org/c/boc/bocode/s432001.html>. Acesso em 17 mar. 2014.

MARIN, J. O. B. et al. O problema do trabalho infantil na agricultura familiar: o caso da produção de tabaco em Agudo - RS. Revista de Economia e Sociologia Rural, Piracicaba, v. 50, n. 4, p. 763-786, out./dez. 2012.

OLIVEIRA, L. F. B.; SOARES, S. D. O impacto do programa Bolsa Família sobre a repetência: resultados a partir do cadastro único, projeto frequência e censo escolar. Rio de Janeiro: IPEA, 2013. (Texto para discussão, n. 1814). Disponível em: <http://www.ipea.gov.br/portal/index. php?option=com_contentEvview=articleĖid=17131 > . Acesso em: 31 jan. 2015.

ORGANIZAÇÃO INTERNACIONAL DO TRABALHO. Acelerar a acção contra o trabalho infantil. 2010. Disponível em: < http://www.ilo.org/public/portugue/region/eurpro/lisbon/pdf/ pub_relatorioglobal_2010.pdf $>$. Acesso em: 18 abr. 2012.

ROCHA, S. O programa Bolsa Família Evolução e efeitos sobre a pobreza. Economia e Sociedade, Campinas, v. 20, n. 1 (41), p. 113-139, abr. 2011. Disponível em: <http://www. scielo.br/pdf/ecos/v20n1/v20n1a05.pdf>. Acesso em: 10 abr. 2013.

SOARES, S.; PIANTO, D. M. Metodologia e resultados da avaliação do programa de erradicação do trabalho infantil. Rio de Janeiro: IPEA, 2003. (Texto para Discussão, n. 994). Disponível em: <http://www.ipea.gov.br/pub/td/2003/td_0994.pdf>. Acesso em: 12 nov. 2012.

Recebido em: 13/04/2015.

Aceito em: 28/10/2015. 